\title{
Evaluation of the Potential Amounts of Dissipated Rare Metals from WEEE in Japan
}

\author{
Eiji Yamasue $^{1}$, Kenichi Nakajima ${ }^{2}$, Ichiro Daigo ${ }^{3}$, Seiji Hashimoto ${ }^{4}$, \\ Hideyuki Okumura $^{1}$ and Keiichi N. Ishihara ${ }^{1}$ \\ ${ }^{1}$ Kyoto University, Kyoto 606-8501, Japan \\ ${ }^{2}$ Tohoku University, Sendai 980-8579, Japan \\ ${ }^{3}$ University of Tokyo, Tokyo 113-8656, Japan \\ ${ }^{4}$ National Institute for Environmental Studies, Tsukuba 305-8506, Japan
}

The potential amounts of dissipated rare metals ( $\mathrm{Au}, \mathrm{Ag}, \mathrm{B}, \mathrm{Ba}, \mathrm{Cr}$, In, Ni, Pb, Sb, Sn, Sr, Ta, Zn and Zr) in WEEE (Cathode Ray Tube TV, liquid-crystal display TV, plasma display panel TV, refrigerator, air conditioner, washing machine, microwave oven and cleaner) have been estimated. For the estimation, the number of WEEE was also estimated using the population balance model. The composition of the WEEE were examined by interviews and the measurement using energy dispersive X-ray diffractometer. The estimated amounts of the dissipation were evaluated by both the ratio of the dissipation to domestic demand and the weight amount of the dissipation by "total materials requirement" (TMR). [doi:10.2320/matertrans.MAW200781]

(Received December 20, 2006; Accepted June 1, 2007; Published July 19, 2007)

Keywords: rare metal, dissipation, evaluation, recycle, population balance model, waste electrical and electronic equipment (WEEE), total materials requirement

\section{Introduction}

Recently, in Japan, regulatory systems for waste electrical and electronic equipment (WEEE) have been established, and necessary technologies for the recycling have been developed, ${ }^{1)}$ resulting in the achievement of the legal recycling rate. For example, in 2003 (3 years after the enforcement of the Home Appliances Recycling Law in Japan), about 10.5 million units of WEEE (TV, refrigerator, air conditioner and washing machine) were taken back at the 380 designated take-back sites, and $99.8 \%$ of them were subjected to recycling processes, followed by the recycling of base metals. In addition, recycling rates of 78, 63, 81 and $65 \%$ were achieved for $\mathrm{TV}$, refrigerator, air conditioner and washing machine, respectively, which were better than legal standards. $^{2)}$

However, as for current shredding recycling processes in Japan, most of rare metals are actually dissipated into recycled base metals. For example, since ferritic stainless steel including $\mathrm{Cr}$, it cannot be separated from other ironbased materials by magnetic separation method, the collected materials including $\mathrm{Cr}$ are diluted by a large amount of pure iron in order to be used as ordinary steel. This indicates not only the downgraded utilization of ferritic stainless steel but also the dissipation of $\mathrm{Cr}$ into the ordinary steel. A similar downgraded utilization and dissipation occurs for other materials and elements, especially for rare metals.

Rare metals, in general, are thinly distributed in the earth, indicating that they need more cost, energy and materials to be produced than base metals. Furthermore, since they are unevenly distributed, supply shortage was frequently brought about and the market of rare metals is drastically changing world-wide. The management of these metals is thus important from the viewpoint of the material-cycle and the strategic resource utilization, especially for resource-poor Japan. In fact, national stockpiling for some rare metals is managed by Japan Oil, Gas and Metals National Corporation (JOGMEC) in order to secure a stable supply. However, only seven kinds of rare metal are stockpiled (Ni, Cr, W, Co, Mo, $\mathrm{Mn}$ and V).

Recycling and reuse of the conventionally dissipated rare metals in WEEE will be one of the effective solutions, and therefore it is important to figure out the amount of the dissipation. Furthermore, evaluations of the dissipation in relation to domestic demand and environmental resource consumption, etc. should be important indices for the development of an adequate recycling scheme. However, from our investigations, few researches ${ }^{3,4)}$ were reported to be considering the impact (amount) of the dissipation of rare metals used in WEEE. Consequently, the aim of this study is to estimate the potential amounts of dissipated rare metals and evaluate the impact of the dissipation in WEEE in Japan.

\section{Research Method}

\subsection{Target elements and WEEE}

The rare metals ( $\mathrm{Au}, \mathrm{Ag}, \mathrm{B}, \mathrm{Ba}, \mathrm{Cr}, \mathrm{In}, \mathrm{Ni}, \mathrm{Pb}, \mathrm{Sb}, \mathrm{Sn}, \mathrm{Sr}$, $\mathrm{Ta}, \mathrm{Zn}$ and $\mathrm{Zr}$ ) and base metals ( $\mathrm{Fe}, \mathrm{Al}$ and $\mathrm{Cu}$ ) were identified by componential analyses later described. In this study, the rare metals were regarded as target elements potentially dissipated. Cathode Ray Tube TV (CRT) (9 samples), liquid-crystal display TV (LCD) (4 samples), plasma display panel TV (PDP) (5 samples), refrigerator (7 samples), air conditioner (9 samples), washing machine (6 samples), microwave oven (6 samples) and cleaner (6 samples) were selected as WEEE. The estimated number of WEEE in the future was previously reported by authors ${ }^{5)}$ based on the report by Tasaki et al. ${ }^{6)}$ The essentials of the estimation will be briefly explained as follows;

The estimation was carried out using the population balance model, ${ }^{7)}$ that is, the difference between the domestic number shipped for a product at fiscal year $t\left(P_{\mathrm{t}}\right)$ and the 
Table 1 The classification of the components for the home electric appliances.

\begin{tabular}{ll}
\hline Matrix & \multicolumn{1}{c}{ Details } \\
\hline Iron & $\begin{array}{l}\text { Pure iron, coated steel, plated steel, PVC* steel, etc. } \\
\text { Copper }\end{array}$ \\
Pure copper, brass, bronze, Cu-Be-Co, \\
conducting wire, etc. \\
Pluminium & $\begin{array}{l}\text { Pure aluminium, Al-Cu, Mn, Mg, Sn, Zn alloys, } \\
\text { conducting wire, etc. }\end{array}$ \\
Other alloys & $\begin{array}{l}\left.\text { Mg alloys, Pb alloys (excluding PWB }{ }^{* *}\right), \\
\text { Zn alloys, magnets, bond magnets, etc. }\end{array}$ \\
Glass & $\begin{array}{l}\text { Electric glass (CRT panel), lead glass } \\
\text { (CRT funnel and CRT neck), LCD glass, PDP glass, etc. }\end{array}$ \\
Plastic & $\begin{array}{l}\text { Polyethylene, polypropylene, poly-styrene } \\
\text { and foamed polyurethane, etc. }\end{array}$ \\
PWB* & $\begin{array}{l}\text { Surface mounted components, lead-free solder } \\
\text { (only 2002), solder, paper/phenol, paper/epoxy, etc. }\end{array}$ \\
Gas & $\begin{array}{l}\text { Chlorofluorocarbon, etc. } \\
\text { Rubber, ceramics, fibre, grease, etc. }\end{array}$ \\
\hline
\end{tabular}

* Polyvinyl chloride, ${ }^{* *}$ Printed-wiring Board

number discarded for the product at fiscal year $t\left(W_{\mathrm{t}}\right)$ equals to the increase of the number in household stock from fiscal year $t-1$ to $t$.

$$
P_{\mathrm{t}}-W_{\mathrm{t}}=N_{\mathrm{t}}-N_{(\mathrm{t}-1)},
$$

where $N_{(\mathrm{t}-1)}$ and $N_{\mathrm{t}}$ indicate the domestic number of possession at fiscal year $t-1$ and $t$, respectively. $N_{\mathrm{t}}$ is derived from the household population ${ }^{8)}$ multiplied by the number of possession per unit household, ${ }^{9)}$ the future values of which were predicted using the logistic approximation. The number of the discarded product is estimated from their lifetime distribution functions. For the estimations of CRT, the effects of alternative products (LCD and PDP) were considered.

\subsection{Determination of composition}

Both the average weights and the constituent materials of the WEEE in 1997 and 2002 were examined by interviews with the Association for Electric Home Appliances in Japan, and the older data was applied to all products produced before 2001 and the later to all products after 2002. The collected data consist of nine major classifications such as iron, aluminium and plastic sorts, as shown in Table 1.

Since most of the rare metals were used as alloys or composites materials, the amounts of them were calculated by considering their compositions. The compositions of CRT glasses (neck, panel and funnel parts) were determined from the reported data. ${ }^{10)}$ The contents of $\mathrm{Fe}, \mathrm{Ba}$ and $\mathrm{B}$ in bond magnet were measured using energy dispersive X-ray diffractometer (EDX). The amount of Ta in Ta capacitor was estimated based on the domestic abundance ratio (in number) of Ta capacitor to whole capacitors, ${ }^{11)}$ the average concentration of Ta in each Ta capacitor ${ }^{12)}$ and the average number of capacitors on the printed-wiring board, the last of which was determined from actual measurements. The contents of $\mathrm{Au}$ and $\mathrm{Ag}$ on the printed-wiring board were determined from the report by Metal Economics Research Institute, JAPAN, ${ }^{13)}$ where no Pd was included on those of the WEEE. The other compositions were determined from
Table 2 Average composition for each element.

\begin{tabular}{|c|c|}
\hline Elements & Containing materials \\
\hline $\mathrm{Au}$ & printed-wiring board ( $\left.30 \mathrm{ppm}^{*}\right)$ \\
\hline $\mathrm{Ag}$ & $\begin{array}{l}\text { Brazing alloy }\left(3 \%{ }^{* *}\right) \text {, lead-free solder }\left(3 \%^{* *}\right) \text {, } \\
\text { printed-wiring board }\left(200 \mathrm{ppm}^{*}\right)\end{array}$ \\
\hline $\mathrm{B}$ & Bond magnets $\left(1 \%{ }^{*}, * *\right)$ \\
\hline $\mathrm{Ba}$ & $\begin{array}{l}\text { CRT panel }\left(3.8 \%^{*}\right) \text {, CRT funnel }\left(0.12 \%^{*}\right) \text {, } \\
\text { CRT neck }\left(0.12 \%^{*}\right) \text {, PDP glass }\left(3.8 \%^{* * *}\right) \text {, } \\
\text { bond magnet }\left(3.7 \%^{* * *}\right)\end{array}$ \\
\hline $\mathrm{Cr}$ & Stainless steel $\left(18 \%{ }^{* *}\right)$ \\
\hline In & Transparent electrode ( $1 \mathrm{~g}$ per $\left.15 \mathrm{inch}^{*}\right)$ \\
\hline $\mathrm{Ni}$ & Stainless steel $\left(8 \%^{* *}\right)$ \\
\hline $\mathrm{Pb}$ & $\begin{array}{l}\text { CRT panel }\left(0.28 \%^{*}\right) \text {, CRT funnel }\left(14.7 \%^{*}\right) \text {, } \\
\text { CRT neck }\left(14.7 \%^{*}\right) \text {, PDP glass }\left(0.28 \%^{* * *}\right) \text {, solder }\left(40 \%^{* *}\right)\end{array}$ \\
\hline $\mathrm{Sb}$ & CRT panel $(0.33 \% *)$ \\
\hline Sn & Solder $\left(60 \%^{* *}\right)$ and lead-free solder $\left(96.5 \%{ }^{* *}\right)$ \\
\hline $\mathrm{Sr}$ & $\begin{array}{l}\text { Ferrite magnet }\left(8.3 \%^{*, * *}\right) \text {, CRT panel }\left(5.5 \%^{*}\right) \text {, } \\
\text { CRT funnel }\left(0.29 \%^{*}\right), \text { CRT neck }\left(0.29 \%^{*}\right)\end{array}$ \\
\hline $\mathrm{Ta}$ & Surface-mounted component ${ }^{*, * *}(0.13 \%)$ \\
\hline $\mathrm{Zn}$ & Plated steel $\left(20 \mathrm{~g} / \mathrm{m}^{2 * * *}\right), \mathrm{Zn}-\mathrm{Al}-\mathrm{Cu}$ alloy $\left(94 \%{ }^{*}\right)$ \\
\hline $\mathrm{Zr}$ & CRT panel $\left(1.4 \%^{*}\right)$, PDP glass $\left(1.4 \%^{* * *}\right)$ \\
\hline
\end{tabular}

*: based on literatures, ${ }^{9,10,13)}$ interview or familiar composition, ${ }^{* *}$ : based on measured value

the interview and/or their familiar compositions. For example, the composition of lead-free solder, which was appeared only in results in 2002, was assumed Sn-3.0 mass $\% \mathrm{Ag}-0.5$ mass $\% \mathrm{Cu}$. Some of the incombustible materials such as $\mathrm{Sb}$, probably included in plastics, were ignored in this study. The estimated compositions are summarized in Table 2.

\section{Results}

Figure 1 shows the estimated number of WEEE. ${ }^{5)}$ The estimated number of the discarded air conditioners, cleaners, refrigerators, washing machines and microwave ovens remains almost constant or slight increase, since the numbers of possession for the products are saturated in Japan. As for CRT, LCD and PDP, while the discarded numbers of the LCD and the PDP increase, those of CRT decrease due to the substitution effect.

The dissipated amounts of elements from the discarded products are shown in Fig. $2(\mathrm{Ba}, \mathrm{Cr}, \mathrm{Ni}, \mathrm{Pb}, \mathrm{Sr}$ and $\mathrm{Zn})$, Fig. 3 (Sb, Sn and $\mathrm{Zr}$ ) and Fig. 4 (Au, Ag, B, In and Ta), while the amounts of $\mathrm{Fe}, \mathrm{Cu}$ and $\mathrm{Al}$, almost of which are recycled, are about 550, 90 and $50 \mathrm{kton} /$ year, respectively. From 2005 to 2015, the potential amounts of dissipated In, $\mathrm{Ag}$ and $\mathrm{Sn}$ show increasing trends due to the increases of transparent electrode (Indium Tin Oxide, ITO) for LCD and lead-free solder (Ag-Sn), while those of $\mathrm{Pb}, \mathrm{Sb}, \mathrm{Zr}, \mathrm{Ba}$ and $\mathrm{Sr}$ show decreasing trends mostly due to the decrease in the usage of CRT glass.

Large amounts of $\mathrm{Cr}, \mathrm{Ni}$ and $\mathrm{Zn}$ are dissipated since the addition of $\mathrm{Cr}$ and $\mathrm{Ni}$ to stainless steel and $\mathrm{Zn}$ to brass or plated steel, etc. are well-established method and better alternatives have not been found. However, it should be noted that recovery systems for $\mathrm{Ni}, \mathrm{Cr}$ and $\mathrm{Zn}$ (stainless steel or plated steel, etc.) by manual disassembly are gradually 


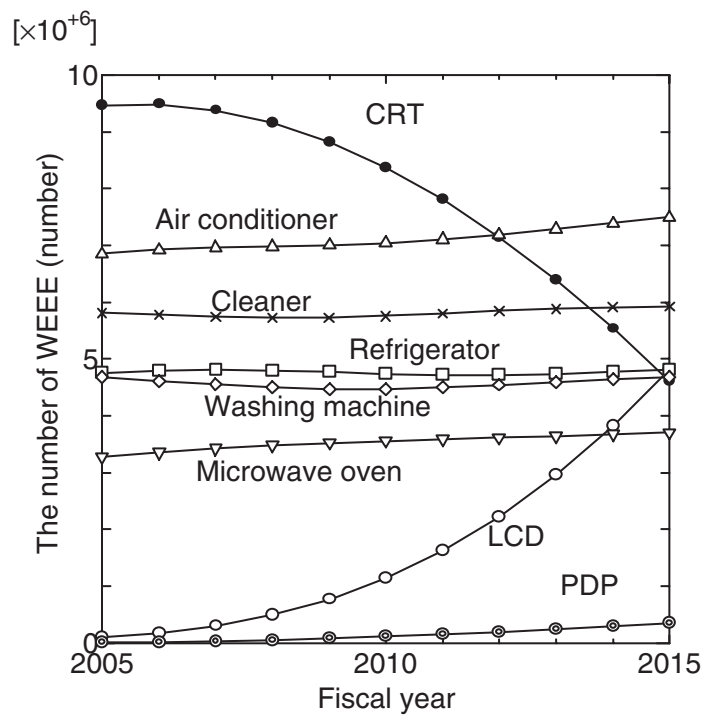

Fig. 1 The estimated number of WEEE. ${ }^{5)}$

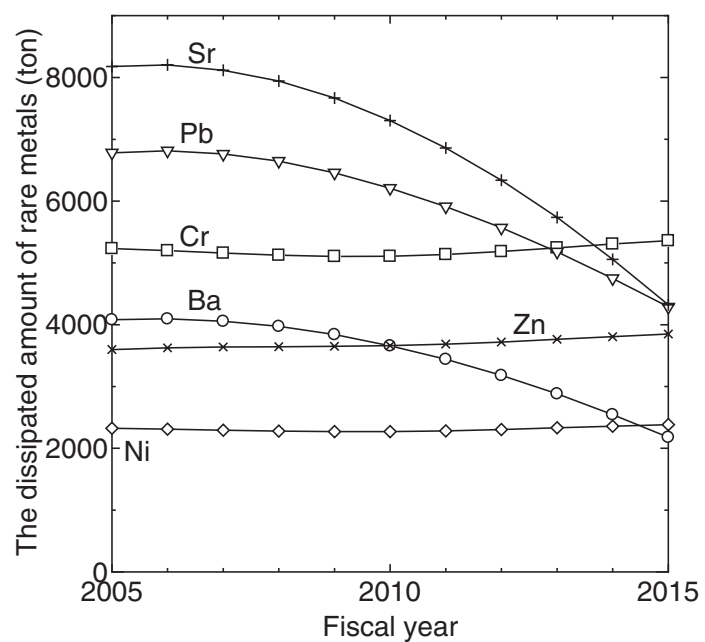

Fig. 2 The potentially dissipated amounts of $\mathrm{Ba}, \mathrm{Cr} \mathrm{Ni}, \mathrm{Pb}, \mathrm{Sr}$ and $\mathrm{Zn}$ from WEEE.

promoted $^{14)}$ compared with those for B, Ba, In, $\mathrm{Pb}, \mathrm{Sb}, \mathrm{Sn}, \mathrm{Sr}$, $\mathrm{Ta}$, and $\mathrm{Zr}$, indicating that a larger amount of $\mathrm{Ni}, \mathrm{Cr}$ and $\mathrm{Zn}$ will be recyclable in the future.

Since it is expected that a larger amount of lead-free solder will be continuously introduced, the dissipated amounts of $\mathrm{Ag}$ and Sn may be underestimated based on the compositional data in 2002. Even in recent years, most conventional solder has not been recycled in Japan due to the problem of cost. In the near future, if the problem of cost is solved for the reason that the expensive $\mathrm{Ag}$ is contained, the recovery of the lead-free solder will be promoted.

As for In, the amount of dissipation increases year by year due to the spread of LCD and PDP, reaching about 35 ton in 2025 through forward estimation. In addition, it should be noted that the size of LCD and PDP is progressively increasing, resulting in more dissipation. The recycling technology of In from ITO is presently under development, and the immediate application to a large-scale recycling plant is expected.

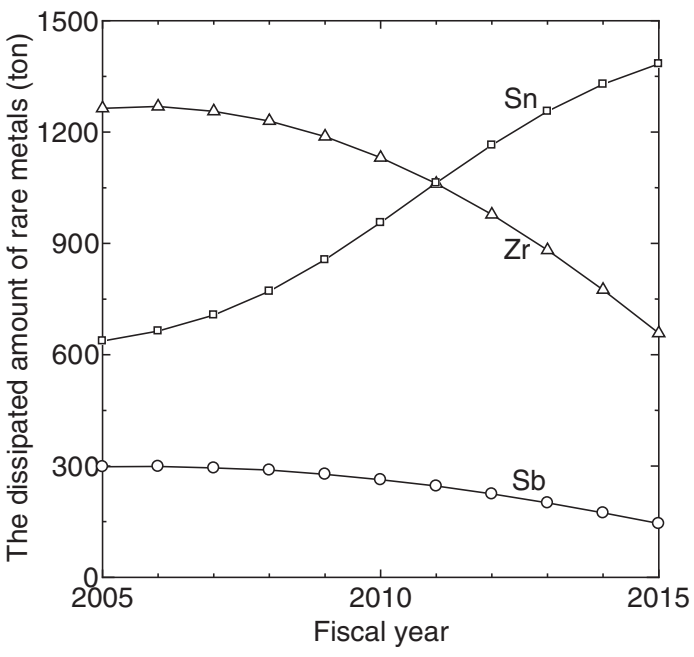

Fig. 3 The potentially dissipated amounts of $\mathrm{Sn}, \mathrm{Zr}$ and $\mathrm{Sb}$ from WEEE.

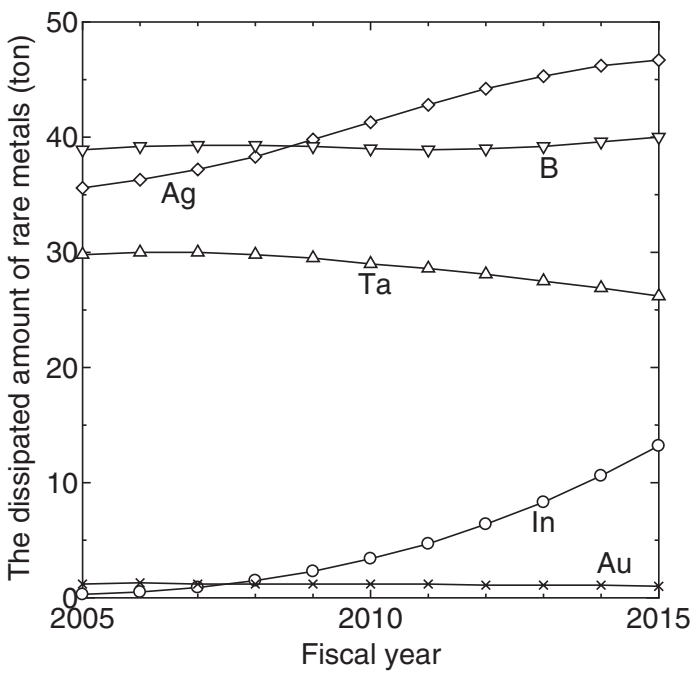

Fig. 4 The potentially dissipated amounts of $\mathrm{Au}, \mathrm{Ag}, \mathrm{B}$, Ta and In from WEEE.

\section{Discussion}

\subsection{Evaluation of the dissipation compared with domes- tic demand}

In order to evaluate the dissipation compared with domestic demand, the ratio of the dissipation to domestic demand (DDD) was proposed, and the amount of domestic demand in 2004 ${ }^{15)}$ was used in this study, where only for Sn the data in 2001 was used. The DDD of target elements is shown in Fig. 5. The larger the DDD becomes, the lower the resource-efficiency is, which indicates that the recycling of the target element is of great significance. In the figure, "average", "maximum" and "minimum" data were determined using the average, maximum and minimum amounts of the dissipation between 2005 and 2015. It is found from the figure that the DDDs of $\mathrm{Ba}, \mathrm{Sr}$, and $\mathrm{Zr}$ show large values (average 15 25\% of domestic demands), while $\mathrm{Ag}, \mathrm{B}, \mathrm{Cr}$, $\mathrm{Ni}, \mathrm{Pb}$ and $\mathrm{Zn}$ show $2 \%$ at most, indicating the priority of the recycling for $\mathrm{Ba}, \mathrm{Sr}$ and $\mathrm{Zr}$ is high. Since the recent domestic demands for $\mathrm{Ba}, \mathrm{Sr}$ and $\mathrm{Zr}$ decrease due to the decrease in the demand of CRT glass, the possibility of overestimation is 


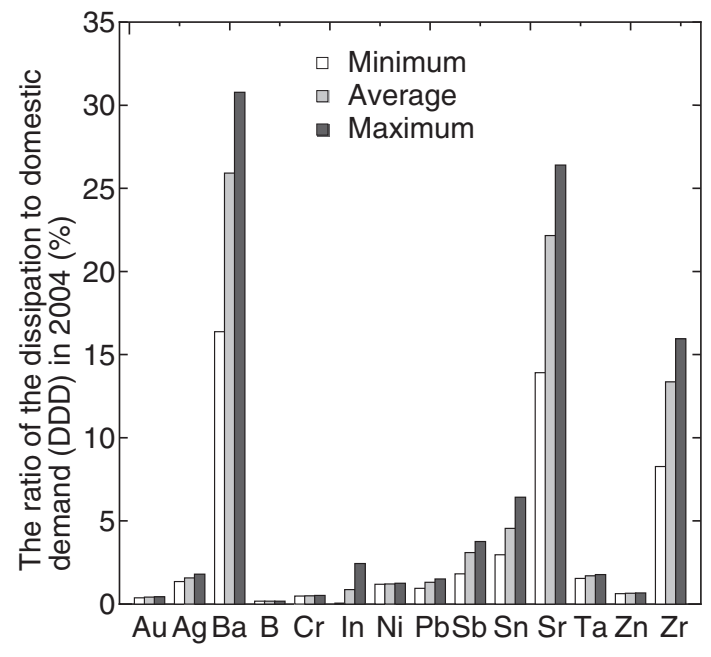

Fig. 5 The ratio of the dissipation to domestic demand (DDD) in 2004. ${ }^{13)}$

considered. However, as an example, the recalculated DDD of Sr using the recent peak value of the domestic demand in $\left.2000,{ }^{15}\right)$ which is $152 \%$ of the domestic demand in 2004 , remains the largest DDD. Much the same is true on $\mathrm{Ba}$ and Zr.

As for $\mathrm{Ba}, \mathrm{Sr}$ and $\mathrm{Zr}$, there are great differences between the maximum and the minimum, reflecting the decrease of the discarded number of CRT. In past days, CRT glasses were horizontally recycled, and the dissipation hardly occurs. However, since the domestic demand of CRT is drastically decreasing (to almost zero in 2011 by our estimation ${ }^{5)}$ ), it is difficult to continue the horizontal recycling within Japan in the future. After May in 2004, with the provision that phosphor materials are removed, CRT glasses were deregulated by the Basel municipal law, indicating a possibility of the horizontal recycling including overseas countries. However, this will bring about the outflow of the resources from Japan. From the viewpoint of resource risk in Japan, urgent development of recovery technology of rare metals, especially $\mathrm{Sr}, \mathrm{Ba}$ and $\mathrm{Zr}$, from the CRT glasses should be considered.

Furthermore, it should be noted that $\mathrm{Sr}$ and $\mathrm{Ba}$ as constituents of ferrite magnets are not recycled either. Excluding the CRT glasses, about 700 and 150 ton of $\mathrm{Sr}$ and $\mathrm{Ba}$, respectively will be dissipated annually, while the amount of Sr occupies about $15 \%$ of the domestic demand for Sr-based ferrite magnets in 2004. Thus, both recovery and reuse of the ferrite magnets are also desirable.

\subsection{Evaluation of the dissipation considering embodied environmental impact}

For the evaluation of the dissipation considering embodied environmental impact, "Total Materials Requirement" (TMR) was employed as a weighting factor. TMR includes not only direct and indirect materials input but also hidden materials flow such as overburden and rock required to produce a target material. ${ }^{16,17)}$ The data of TMR used in this study is summarized in Table 3. ${ }^{3,18)}$ Although there is no available TMR data of $\mathrm{Ba}$, the value was estimated to be 460 (ton/ton) from that of congener, $\mathrm{Sr}$ (500 ton/ton), using following relation; ${ }^{18)}$
Table 3 TMR of $\mathrm{Au}, \mathrm{Ag}, \mathrm{B}, \mathrm{Ba}, \mathrm{Cr}, \mathrm{In}, \mathrm{Ni}, \mathrm{Pb}, \mathrm{Sb}, \mathrm{Sn}, \mathrm{Sr}, \mathrm{Ta}, \mathrm{Zn}$ and $\mathrm{Zr}^{3,16)}$

\begin{tabular}{cr}
\hline Element & TMR (ton/ton) \\
\hline $\mathrm{Au}$ & 1100000 \\
$\mathrm{Ag}$ & 4800 \\
$\mathrm{~B}$ & 140 \\
$\mathrm{Ba}$ & 460 \\
$\mathrm{Cr}$ & 26 \\
$\mathrm{In}$ & 4500 \\
$\mathrm{Ni}$ & 260 \\
$\mathrm{~Pb}$ & 28 \\
$\mathrm{Sb}$ & 42 \\
$\mathrm{Sn}$ & 81 \\
$\mathrm{Sr}$ & 500 \\
$\mathrm{Ta}$ & 6800 \\
$\mathrm{Zn}$ & 36 \\
$\mathrm{Zr}$ & 550 \\
\hline
\end{tabular}

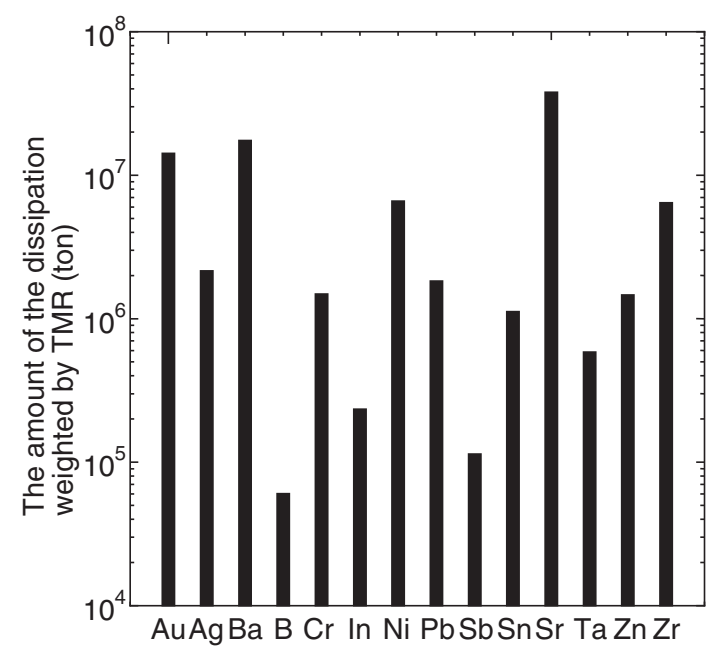

Fig. 6 The amount of the dissipation weighted by TMR.

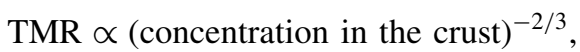

where the concentrations in the crust for $\mathrm{Ba}$ and $\mathrm{Sr}$ are 425 and 375 ppm, respectively. ${ }^{19)}$

Figure 6 shows the sum of the dissipation weighted by TMR from 2005 to 2015. A larger amount of the weighted dissipation indicates a larger amount of materials flow, which indicates a greater significance of the recycling of the target element. The impacts of $\mathrm{Sr}$ (38 million ton-TMR), Ba (17 million ton-TMR) and $\mathrm{Au}$ (14 million ton-TMR) are outstanding. The impact of $\mathrm{Sr}$ is equivalent to 4.8 million ton of $\mathrm{Fe}$ (which TMR is 8 (ton/ton)), corresponding to about $4 \%$ of annual production of crude steel in Japan. It is suggested that the efficient utilization of $\mathrm{Sr}$ and $\mathrm{Ba}$ in discarded CRT glasses is a pressing issue, and the recovery of $\mathrm{Au}$ from the printedwiring board should be actively promoted. On the other hand, despite low TMR, $\mathrm{Ni}, \mathrm{Pb}, \mathrm{Cr}$ and $\mathrm{Zn}$ show relatively large impacts because the absolute amounts of the dissipations are too large. It is also suggested that efforts to recycle and/or reuse the constituent materials which include the above elements are required. 


\section{Conclusion}

In this study, the potential amounts of dissipated rare metals (Au, Ag, B, Ba, Cr, In, Ni, Pb, Sb, Sn, Sr, Ta, Zn and $\mathrm{Zr}$ ) in WEEE have been estimated from 2005 to 2015. The dissipated amount of In shows an increasing trend, while those of $\mathrm{Pb}, \mathrm{Sb}, \mathrm{Zr}, \mathrm{Ba}$ and $\mathrm{Sr}$ show decreasing trends. According to the ratio of the dissipation to domestic demand (DDD) in 2004, the DDD of $\mathrm{Ba}, \mathrm{Sr}$, and $\mathrm{Zr}$ are high (average 15 25\% of domestic demands), while those for $\mathrm{Ag}, \mathrm{B}, \mathrm{Cr}$, $\mathrm{Ni}, \mathrm{Pb}$ and $\mathrm{Zn}$ show $2 \%$ at most. The evaluation of the dissipation considering embodied environmental impact was carried out based on the sum of the dissipation from 2005 to 2015 weighted by "total materials requirement" (TMR). The impacts of $\mathrm{Sr}, \mathrm{Ba}$ and $\mathrm{Au}$ show 38 million ton-TMR, 17 million ton-TMR and 14 million ton-TMR, respectively, which are the largest among the rare metals. It is proposed that the efficient recycling of $\mathrm{Sr}$ and $\mathrm{Ba}$ from WEEE is a pressing issue, and the recovery of $\mathrm{Au}$ from the printedwiring board should be actively promoted.

\section{Acknowledgement}

This research was supported by a Waste Management Research Grant from the Ministry of the Environment, Japan. Project number: K1810 (2006), Project leader: Dr. Seiji Hashimoto and the project name is "Development of material stock account framework and its application: strategies for waste/resource management".

\section{REFERENCES}

1) Clean Japan Center: Guidebook for Recycling-Oriented Society (2005) p. 23.
2) Ministry of the Environment: Kankyo-Hakusyo (in Japanese) (White paper on sustainable society) (2004).

3) K. Halada: Report of Joint Symposium by The Iron and Steel Institute of Japan and The Japan Institute of Metals (2005) pp. 21-28.

4) K. Nakajima, K. Yamamoto, K. Nakano, K. Kuroda, K. Halada and T. Nagasaka: J. Life Cycle Assess., Jpn. 2 (2006) 341-346.

5) E. Yamasue, K. Nakajima, H. Okumura and K. N. Ishihara: J. Jpn. Inst. Metals 70 (2006) 611-614.

6) T. Tasaki, M. Oguchi, T. Kameya and K. Urano: J. Jpn. Soc. Waste Management Experts 12 (2001) 49-58.

7) K. Kakudate, Y. Adachi and T. Suzuki: Sci. Technol. Adv. Mater. 1 (2000) 105-116.

8) National Institute of Population and Social Security Research: Nihonno-Setaisu-no-Syouraisuikei (in Japanese) (2005).

9) Association for Electric Home Appliances: Kaden Sangyou Handbook 2005 in Japanese (Handbook of Electric Home Appliance Industry) (2005).

10) H. Inano, Y. Hashimoto and K. Kudou: Hokkaidoritsu Kogyo Shikenjo Hokoku in Japanese (Report by Hokkaido Industrial Research Institute) 304 (2005) 71-77.

11) Ministry of Economy, Trade and Industry: Keizai Sangyo Kikai Tokei (in Japanese) (Statistics of Equipments by Ministry of Economy, Trade and INdustry) (2004).

12) Industrial Rare Metals: Annual Review 2004, Arumu publishing, 120 (2004).

13) Metal Economics Research Institute, JAPAN: IT kiki ni kansuru syuyou rare metal no recycle doukou, (2001) 136-142.

14) N. Takada, K. Taga and D. Ueyama: Toshiba Review 591 (2004) 3437.

15) Japan Oil, Gas and Metals National Corporation, Materials Flow 2005 (2005).

16) A. Adriaanse, S. Bringezu, A. Hammond, Y. Moriguchi, E. Rodenburg, D. Rogich and H. Schutz: Resource Flows; The Material Basis of Industrial Economics (1997).

17) European communities: Economy-wide material flow accounts and derived indicators, A methodological guide (2001).

18) K. Halada, K. Ijima, N. Katagiri and T. Okura: J. Jpn. Inst. Metals 65 (2001) 564-570

19) National Astronomical Observatory of Japan: Rika nenpyo (Chronological Scientific Tables) (Maruzen Co., Ltd., 1996). 